Lars Erik Zeige*

\title{
From Saussure to sociology and back to linguistics: Niklas Luhmann's reception of signifiant/signifié and langue/parole as the basis for a model of language change
}

DOI 10.1515/sem-2015-0067

\begin{abstract}
The article highlights a semiotically relevant aspect of Niklas Luhmann's Theory of Social Systems: its reception of the Saussurean dichotomies signifiant/ signifié and langue/parole. Luhmann's position is weighted against the Cours as well as Saussure's original writings, sampling their approaches to form, meaning, the sign's two-sidedness, and the relation of linguistic structure and speech events. Ultimately, the article proposes a social ontology of linguistic abstraction in line with general semiology that explains the motility of language through communication, thereby accounting for variability and optionality. It also indicates as to how the theoretical framework can feed into a model of linguistic description.
\end{abstract}

Keywords: linguistic sign, Ferdinand de Saussure, Niklas Luhmann, theory of social systems, communication, language change

\section{Introduction}

Although "system" is presumably one of the most widely-used terms in linguistics, knowledge of contemporary systems theory is by no means abundant. This holds especially true for social systems theory. In linguistics, there is a certain familiarity with the works of Talcott Parsons (1902-1979), the central figure in this field in the middle of the twentieth century (cf. Milroy and Milroy 1992: 3). Between 1960 and 1961, the German sociologist Niklas Luhmann (1927-1998) spent a sabbatical at Harvard, where he met and studied under Parsons. Luhmann's early works are based on Parsons' structural functionalism. An increasingly critical assessment of the theoretical foundations, however, led Luhmann to revise and expand his own "Theory of Social Systems," which he laid out in numerous monographs and articles from the beginning of the 1980s onwards (cf. the publication list in Baraldi et al. 1999: 218-248). It differs from Parsons' view in its strong emphasis

*Corresponding author: Lars Erik Zeige, Humboldt-Universität zu Berlin, Berlin, Germany, E-mail: lars.zeige@rz.hu-berlin.de 
on operational closure and the procedural character of systems. Today, Luhmann's theory is a generally accepted sociological framework; however, his work is not easily accessible. It is extremely dense and presupposes many theory-laden terms in sometimes rather idiosyncratic German terminology, e.g., the terms Sinn and Bedeutung and the whole weight of philosophical tradition since Husserl's phenomenology or his use of Form and Medium in the tradition of Gestalt psychology, not to mention that every reader has to shake off the generic meaning of the words from which these terms are derived. The terminology and complexity of his work poses particular difficulties for any attempt at translation, which might be the reason why Luhmann's theory has to this day been almost exclusively published in German. While being an accepted part of sociological curricula in continental Europe since the 1980s, only now are publications from the US starting to apply his theory (e.g., Fontdevila et al. 2011). It can be assumed that, in the long run, the merits of his theory will outweigh its difficulties.

Designed as a universal theory, it includes a critical discussion and application of many issues prevalent in linguistics, such as form/matter, meaning, symbolic structures and signs, part/whole relationships, consciousness, complexity, action, etc. (SS 12). But there is one hitch: Unfortunately, the keen eye of the linguist misses an explicit theory of language. Luhmann himself seems to have had an interest in grammatical structures, as some parenthetical passages suggest, e.g., on the Ancient Greek aorist (GdG 220 n. 47). However, as Luhmann (1987) argues, the overall construction of his theory makes a discrete theory of language unnecessary. His comprehensive theory of "generalized symbolization" subsumes linguistic structures quite naturally. So, if language was not at all neglected in Luhmann's work, it is still less prominent than the linguist might have hoped. Zeige (2011) therefore gathered and collated chapters, passages, and footnotes on language to question them, put them in context, and make available a coherent system theoretical perspective on language. In general, it can be said that Luhmann offers very interesting, non-canonical perspectives on and answers to many central linguistic questions. To linguists, I strongly suggest reading Luhmann. To illustrate this point, this article will discuss Luhmann's system theoretical account of the linguistic sign.

There is another linguistically relevant aspect of Luhmann's work, however: his reception of Saussurean linguistics and the theoretical integration of some of its components, most prominently signifiant/signifié and langue/parole. This makes it possible to discuss the differences in Luhmann's approach by relating his position to established linguistic thought. It would render the text indigestible, though, to extend the discussion beyond that to the variety of present-day frameworks in linguistics. Therefore, this article focuses on the two poles of Saussure and Luhmann alone. I trust that interested scholars will take up those arguments, friendly or adversarial, that matter to them. 
After a brief contextualization of Luhmann's theory (Section 1), the following section will sample the notions of meaning and form, as well as the sign's status as a duality (Section 2). Section 3 will then approach the relation between structure and event. As his theory is both sociological and system theoretical, Luhmann treats the sign as both communication-based and dynamic. Therefore, the discussion will finally be carried over to concluding remarks on a social approach to language change and an outlook on its applicability. Thus, the linguistic sign and the relation between structure and event pose interesting cases of the repeated transfer of an idea in the history of science. We will proceed from Saussure to sociology and, if you will follow this idea, from Luhmann back to linguistics.

\section{Some prerequisites for understanding Luhmann}

System theoretical thinking has, over the course of its development, constantly renewed itself under the influence of other disciplines. Modern systems theory has progressed since the beginning of the twentieth century from physics to cybernetics, and from there to biology, psychology, and finally sociology. It has thereby evolved into a rich explanatory means of accessing a wide range of complex and self-organized objects. There are open and hidden conjunctions between systems theory and linguistics, where fundamental ideas are transferred into the language sciences. What can be regarded as the main developmental stages of modern systems theory is illustrated by the following very short and exemplary history: (i) system as order, (ii) the question of the emergence of that order in processes, and (iii) the focus on the properties of these processes.

\subsection{Order}

The term "system" has become established since post-Socratic philosophy as gr.

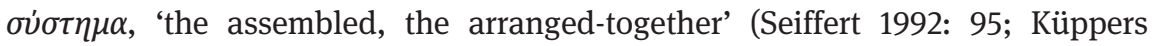
1996: 11-96). It refers to concrete or abstracted objects aligned in an orderly fashion, or: elements in relations. The elements, their properties and positions alone, simply describe an accumulation of isolated objects. Only when observed in their relations do these elements constitute a meaningfully arranged complexity, a "system." Where relations connect elements, there is the inside of a system. Where the relations end, the environment of the system begins. This is commonly known as the "structural concept" of a system (Ropohl 1978: 15). As 
long as the whole of the system is viewed as the mere sum of its parts, "system" and "structure" are identical. In linguistics, the structural concept underlies the structuralist notion of system, where the main descriptive task is to triangulate the systemic value of every element by its syntagmatic and paradigmatic relations in the entirety of all system elements. Thus, the order of a language system emerges. We will expand on that in the discussion below.

\subsection{Process}

Another constitutive source of systemic thinking since antiquity stems from philosophical considerations of the emergence of things and life, especially in cases where elements obtain their order autonomously, i.e., by self-organization (Paslack 1996; Küppers and Paslack 1996: 45). The necessary presumptions of such a view of complex objects can be explained by an experiment conducted by the French physicist Henri Bénard (1874-1939) for his dissertational work on pattern formation in liquids (1901). A thin layer of a highly viscous liquid is heated in a Petri dish. A vertical flow occurs between the heated ground and the cooler surface, but the liquid does not circulate in its entirety and instead a honeycomb-like structure of convection cells is formed. Bénard is credited with the initial identification of the specific process of structure formation at work in his experiment: The structure of what is now called "cellules de Bénard" in his honor does not rely on the liquid's molecular structure or the shape of the Petri dish. Rather, the external heat source initiates a thermal imbalance that causes a flow. This flow is a procedural operation within the system, where the differences in temperature within the liquid, gravity, the laws of motion, the viscosity of the liquid and other factors combined lead to the observable structure (Küppers 1996: 122-148). It is, firstly, a case of self-organization, since the structure depends on the conditions of the process alone and is only indirectly dependent on the environment in that the continued heating perpetuates the internal imbalance of temperature. Second, however, the stable comb-like structure observable on the global level depends on the continuous local dynamics of heating, ascension, cooling, and descent in every convection cell. Take the energy source away, and the structure vanishes. Change the temperature, and the cells will change their size within certain margins of tolerance or the liquid will slide into chaotic flow altogether. In other words, one has to account for the fact that a given structure, although seemingly stable, cannot be explained by the properties of its elements-in-relations. It may rely on a process of continued self-reproduction of its basic elements and be in a state of "dynamic stability." Linguistic theory has participated little in the idea of self-organization. In 
Keller's model of language change as an "invisible hand” process (1994 [1990]), for example, observable linguistic structures (convection cells) can arise as involuntary consequences of human actions that have been aimed to achieve other, namely, personal social goals (properties of the molecules), in communication (flow). The idea that language needs to be carried out in an actual communicative process seems, under the aegis of systems theory, a particularly important one.

\subsection{Properties of the process}

Any systemic account of a complex object now has to give a sufficient explanation of how exactly the system's process facilitates the system's structure of elements in relations. The description of the elements-in-relations becomes a prerequisite of that task. It was in biology that this model was comprehensively developed. In the 1970s, the Chilean neurobiologists Humberto R. Maturana (b. 1928) and Francisco Varela (1946-2001) sought a formal definition for life and made use of early cybernetics and its attempts to describe organisms as autonomous dynamic entities (Varela and Maturana 1974). On the one hand, life had to consist of elements-in-relations, which made the model system theoretical. On the other hand, they devised the elements as dynamic-stable entities. For example, the human digestive system decomposes the food we eat. Only elements that can be processed in bodily functions (e.g., fat, protein, carbohydrates) can pass the system/environment border of the body, the intestinal wall. According to its own complex bodily functions, from neural regulation and metabolism to the biochemical processes of every cell, the body synthesizes from the ingested basal elements the amino acids, tissues and organs that make up the body. It reproduces "self-referentially." In addition, these operations of the system continue in principle without interacting with the system's environment, or: the system is "operationally closed." With closed self-referential reproduction, the perspective is now reversed: The elements-in-relations do not explain the system, the system explains its elements-in-relations. The globally stable system "organism" reproduces in locally dynamic processes. The continuity of the system is facilitated by the discontinuity of its elements. Technically speaking, this is not a model of structure formation, but a model of continued structural self-reproduction. To mark this difference, Maturana and

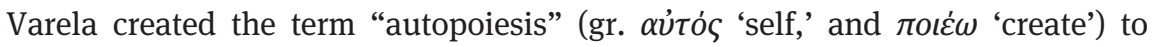
substitute the general term "self-organization." To be "autopoietic" is, according to them, the defining criterion for life. Co-operating with Heinz von Foerster (1911-2002) and Gregory Bateson (1904-1980), Maturana and Varela (1980, 1984) 
brought together research on complex systems and neurophysiological and neuropsychological research. They claim that the mind also reproduces autopoietically, when thoughts and ideas are aligned as elements. Every thought reproduces the dynamic-stable entity "consciousness," whereas the structure and processes of the mind determine the production of thoughts. Any model of language change that explains the development of linguistic structures through language acquisition uses conceptions of cognition, processing, and consciousness that point to operationally closed self-referential reproduction. The acquisition of linguistic structure is analyzed as an accomplishment of the interpreting mind. It is already possible to group parts of Hermann Paul's "Principles" into this broader range of theories (cf., e.g., Paul 1960 [1880]: III §42; see Auer 2007 for discussion). Also in Generative Linguistics, the several versions of the general idea "input + UG" (Chomsky's "evaluating metric" of 1965, his parameters of 1981, Gibson's and Wexler's error-based “Triggering Learning Algorithm” of 1994, or Lightfoot's 'Cue-Based Acquisition' of 1991) only define the instances of structure formation in different ways, but leave untouched the basic principle of internal construal. In cognitive models outside the Generative framework, like Langacker's Cognitive Grammar, the description of a language is seen as "a substantive hypothesis about its actual cognitive representation...” (Langacker 1987: 56) This conjunction presupposes the autopoiesis of the mind ante litteram. For the remaining discussion, let us take as given an operational (instead of structural) notion of systems with three properties of autopoietic reproduction: dynamic stability, operational closure, and self-referentiality.

Niklas Luhmann applied the idea of autopoiesis to social order. In his theory, society disintegrates into an arrangement of closed and self-referentially reproducing social systems, each of which reproduce in a process of communication. Communication thereby constitutes a demarcation: Where communication ends, a social system ends. The smallest form necessary to maintain communication is face-to-face interaction. But also higher aggregated and longer lasting social systems - from any substructure of society to society as a whole - are constituted by communication. A system theoretical sociology treats society thus as a case of social systems (SS 18; Kieserling 1996: 288), regardless of the public demand for a term for society as a whole (SS 555).

This notion of communication breaks with traditional sender/receiver-based models known since Bühler's “organon model” (1978 [1934]) and Jakobson (1960), but also with functional speech act theory as in Austin (2003 [1962]) and Searle (1969). It substitutes the "transmission" metaphor and combines accounts of communication that have been produced in neighboring disciplines, like computer science, cybernetics, and sociology (Mead 1934 for sociology; 
Shannon and Weaver 1972 [1949]; Wiener 1948 "feedback"), into a united understanding of communication as a self-obtained process (Schützeichel 2004; Baecker 2005: 25). By applying Luhmann's theory, linguistics would acquire a communication model that revises the role of the individual in communication. From Luhmann's system theoretical point of view, three types of autopoietic systems are involved in communication: biological, cognitive, and social systems, each specified by their process type (metabolism, cognition, communication). The biological endowment of the speaker/listener and material side of processing are part of a biological system, whereas the emergent, non-material side of phenomena such as perception and processing, acquisition, storage, accessability, and activation refer to cognitive systems. The social system, finally, processes actualized communicative events and thus facilitates linguistic structure. It must be stressed that these system types, following Maturana's and Varela's original idea of autopoiesis, reproduce in an operationally closed manner and self-referentially. Consequently, they are part of the other systems' environment. They do not and cannot contribute any of their own operations to the operations of other systems (GdG 103-104; ZaF 53-54). Cells do not think, cognition does not communicate, and communication does not live. Likewise, two systems of the same type cannot transmit or share their elements. For example, in the case of ideas, neither the neural activity of one brain nor the thoughts of an individual can be introduced into another individual - this would constitute telepathy. Ideas must be communicated and communication follows the structure and processes of social systems. The implication of operational closure and system/environment boundaries is that biological and cognitive states cannot be part of the process of communication.

With an established cognitive tradition in linguistics, this may sound bewildering. It seems too obvious that biological, cognitive, and social systems, although distinct in their operations, require one another. The cognitive system would not work without firing neurons and veins that pump oxygen into brain cells. A phoneme system can only include phonemes that we are able to produce physiologically. The meaning of signs can only be a concept that we are able to imagine. However, as Luhmann rightly points out, one system can be the condition of possibility of others (SS 60). That biology and cognition are part of the infrastructure of communication does not therefore imply mutual determination. In Bénard's experiment, the Petri dish and the Bunsen burner did not determine the shape of the structure, but were necessary to maintain it. Likewise, physiological and cognitive outer frameworks are uninterestingly broad in comparison to the intricate shapes and changes of forms of communication. Instead of observing structures of communication as a hypothesis for cognitive structures, the relationship between biological, cognitive, and social 
systems should rather be analyzed as a form of co-evolution and structural coupling (Luhmann 1977; SS 289; GdG 100, 211). It allows these systems to operate in accordance with their environment without being mutually determined. When individuals communicate, a shared world is established that cannot be reduced to structures and processes of the participating biological and cognitive systems. A social system with its own structural properties emerges (GdG 191) and the forms of communication (in sociological thinking, not only languages, but also the exertion of power, money trade, dispensation of justice, science, and others) have evolved as generalized symbolic structures of these social systems.

Linguistics has so far neither collaborated nor contributed to research in this latest developmental stage of systems theory, in contrast to literary science, for example (Stanitzek 1997; Binczek 2002). This is particularly surprising, because of all theoretical approaches to systems, this is the one that explicitly covers communication, media and grammatical structure, the linguistic sign and other concepts close to the linguist's heart. In addition, it is a dynamic theory, suitable to explain variation and change. The idea of autopoietic social systems also mitigates the central sociological problem of how to explain the emergence of sociality, as it dissolves the micro-macro problem, i.e., the mutual determination of basal interaction on the one hand and society on the other (Alexander 1987; Greve 2008). This echoes the linguistic micro-macro problem of individual speaker behavior on the one hand and styles, registers, dialects and national and world languages on the other. It seems obvious why all these aspects should be of interest to linguistic modelling.

When discussing Luhmann's reception of Saussurean ideas in the following sections, it seems important to sound a note of caution first. This is not an attempt to haphazardly relate elements of Luhmann's theory to those in Saussure's writings. The relations themselves have been established by Luhmann, and by quoting Saussure and referring to some of his ideas. The intention here is to elaborate on individual notions and their theoretical background on both sides to an extent that the reasoning that lead to these relations can be motivated. It should also be pointed out that Luhmann's position is not seen as a mere system theoretical re-interpretation of Saussurean concepts. There are arguments, as discussed by e.g., Scheibmayr (2004: 143) for the sign system, to regard Saussure's static concept of elements-in-relations and Luhmann's process-based theory as predominantly incommensurable. On the one hand, we will discuss to what extent it is possible or even necessary to challenge a perception of Saussure's linguistic sign as static. On the other hand, it is possible to show that Luhmann's notions are true hermeneutical inventions within the complex fabric of a state-of-the-art theory. 


\section{The linguistic sign as form}

In the following paragraphs, we will investigate the linguistic sign as a twosided form, based on the two following statements of Luhmann: The sign is "the form of the difference between signifier and signified" (ZaF 49, my translation) and "... linguistic communication processes meaning in the medium of sound" (GdG 213, my translation). To understand the nature of language and the linguistic sign in the Theory of Social Systems, the paragraphs of this section will elaborate on the notions of difference, meaning, form, and sign, as well as the obvious proximity to Saussure's linguistic sign. Section 3 will interpret the procedural perspective ("processes meaning”) on communication.

\subsection{Difference}

Every component of Luhmann's theory is subjected to "form analysis" following the "calculus of form" of the British mathematician and philosopher George SpencerBrown (b. 1923). In his main work Laws of Form (1969), Spencer-Brown proves a universal calculus whose extreme formalism made it very attractive to cybernetics and hence also systems theory. The next paragraphs will only introduce the terms indispensable for the discussion. The laws of form are based upon two universals, distinction and indication: ${ }^{1}$ By drawing a distinction, spaces, states, or contents can be indicated on each side of the boundary. This operation also constitutes a demarcation, however, by which one side of the boundary is distinguished from the other. Spaces, states or contents from one side of the boundary are "marked" and "unmarked" on the other (Spencer-Brown 1969: 5-6). As something distinct, spaces, states or contents become operable - they are not traditional "objects," but rather forms of differences that are the result of the operations of distinction and indication. Imagine lots of unsorted objects on a beach. You draw a circle around some of them. By drawing the distinction, these objects are indicated. Perhaps they possess the same shape or color or there are just five objects in the circle. Then the state or content that is indicated is, e.g., "rectangle," or "blue," or "five.” The indicated states can also be given names: rectangle, blue, or five. In addition, in chapter twelve of his book, Spencer-Brown proves that the operation of distinction can be applied to forms that already are the result of distinction. The distinction "re-enters" the form, which makes the form self-referential. However, the universal figure "re-entry" also causes a paradox: The application of the calculus to an expression $e$ creates an expression $e$, that is different from $e$. Spencer-Brown suggests that the dimension of time has to be

1 Cf. for criticism Glanville (1988) and Cull and Frank (1979). 
included, which makes the repeated application of the calculus a process and its mathematical results its developmental stages (Spencer-Brown 1969: 54-68). Spencer-Brown's mathematical calculus thus acquires a procedural dimension.

Luhmann subjects all elements that enter his theory-building process to formal analysis and reconstructs them as forms of differences. For example, a system is the form of the difference that has been differentiated from its environment. It is a two-sided form of system/environment. Thus, he creates a homogeneous theoretical architecture of independent but hierarchically structured "two-sided forms" (Zwei-Seiten-Formen, WdG 79-80). Every two-sided form follows this general principle:

An $x$ is the form of the difference between $x$ and $y$

Certain characteristics become apparent: In a two-sided form, marked and unmarked states are distinguishable but inseparable. The $x$ is at the same time the form as a whole, as well as the identity of the differentiated (the marked state). It includes itself. In addition, the marked state is only marked in opposition to everything that is unmarked. Consequently, the unmarked state always remains co-present when the marked state is evoked. The two-sided form is therefore a true duality. For the same reasons, it is also a paradoxical form. It therefore has the ability to call for attention and thus to transport meaningful differences. It is, as a form, conspicuous.

\subsection{Meaning}

Luhmann utilizes the procedural character of Spencer-Brown's calculus and brings it together with the idea of closed and self-referentially reproducing systems. He equates the self-observation of autopoietic systems with the re-entry of distinction and indication (cf. also Varela 1975). In this way, cognitive and social systems gain the ability to observe their own operations (self-reference) and the ability to recognize the boundaries of their own operations, i.e., the difference between themselves as a system and their environment (external reference). Processing the difference between self- and external reference, the system/environment border re-enters the system's process and puts the system's own operations into context, i.e., it gives them "meaning."2 Only cognitive and

2 The basis is Edmund Husserl's (1859-1938) phenomenology, cf. SS 92 and GdG 44. From it the term Sinn is adapted. As common to English literature on the matter, meaning incorporates both Sinn and Bedeutung, somewhat obnubilating the phenomenological dimension of Sinn as being "based on the senses" and "sensual intuition." This article, however, follows the common usage. 
communicative systems possess this ability; they are "meaning-constituting systems" (GdG 50-51). Here, the calculus turns into a mathematical epistemology when perception, knowledge, and communication are construed as the internal calculation of reality (Simon 1993: 45).

In the manner customary to Luhmann's theory building, meaning is developed as a difference. The form of meaning is the difference between actuality and potentiality (SS 64, 92; GdG 44; ZaF 62-63). When meaning is processed in communication, a selection is made by distinction and indication. The "marked state" is actualized meaning for communication. The meaning of what was selected does not so much lie in the information value of the item itself, but in the fact that it was chosen in favor of all other selections which could have potentially been chosen ("unmarked state"). The potentiality stays co-present in the actualized (GdG 49) and introduces an element of uncertainty to all communication. It is the contingency of selections, the potential to be different, that has forced social systems to generalize reliable references of meaning into symbols, for example coins in economic communications, but most effectively linguistic signs (GdG 47). Using symbolically generalized media like language allows communication to stabilize meaning and to return at any given moment of communication to more or less unambiguous constellations of meaning. To that end, the form of meaning operationalizes another difference: the difference between form and medium.

\subsection{Form and medium}

As one of the later parts of his theoretical work (cf. Luhmann 1992; ZaF 64-65; KdG 165; GdG 190; WdG 53, 181), Luhmann introduces his medium theory on the basis of Gestalt-theoretical works by Fritz Heider (1896-1988). Heider, in his 1926 essay "Ding und Medium," asks why we see the object but have no perception of the medium of light, although it is generally recognized since Aristotelian metaphysics that the object of recognition and the object in the world are mediated by some elementary substance. ${ }^{3}$ In his media theory, Heider interprets the physical process of transmission in a medium as symbolic, illustrated by the following analogy: A cloth, laid out flat on a surface, has no form. But grab an object with it, and the type of fabric determines how much of the object's details you can perceive through it. A sheet of silk will allow for more details to be

3 Note, though, that Aristotle's conception of perception is not a general media theory. He takes $\tau \grave{~} \mu \varepsilon \tau \alpha \xi \dot{v}$ "the in-between," from Platonian epistemology and sees mostly the four elements in this position; cf. Aristotle (1955). 
perceived than a piece of rough linen. The apparent unity of the object is facilitated by the multitude of fibres. ${ }^{4}$ The medium thus exerts a constructive influence on perception, but has itself no information value and is therefore not perceived. The same, according to Heider, applies to visual and acoustic perception in which the intrinsic oscillation of air molecules and light waves is altered. The divergence from the natural state of the medium is prominent and forces an observer to perceive. ${ }^{5}$ The forms imprinted in a medium, in other words, "point a finger at their source"; they are signs (Heider 2005 [1926]: 43-45). Every form of transmission in any medium is therefore symbolic in nature, and human perception and cognition are predisposed to locate signs - meaningful constellations of form (Heider 2005 [1926]: 110-111) - and to disregard the medium.

Heider's theory has been received not just as a concept of visual perception, but also as a theory of media in general. It has consequently been applied to language by Luhmann (GdG 195-202). Communication within the vocal-auditory medium is scanned by an observer for imprinted alternations of sound that must be automatically interpreted as signs carrying actualized meaning, whereas the medium itself is not perceived. Someone who speaks also communicates. Luhmann turned Heider's idea into a two-sided form: A form is the form of the difference between form and medium. As the difference is itself a form, it functions recursively: The forms of one difference can serve as a medium to others (GdG 59, 197). Grammatically, morphological forms are imprinted on the medium of phonemes, syntactic forms are imprinted on the medium of morphemes, and so on (Esposito 1993: 117-118). Semiotically, language as a whole is a communicative medium on which the forms of meaning (see Section 3.2) are imprinted. The communicative system, so to speak, lays the cloth of the linguistic medium onto the meaning to make meaning as form operable (WdG 53-55).

\subsection{The linguistic sign}

For a form analytical account of the linguistic sign, Luhmann brings together Heider's media theory and Saussure's linguistic sign: "Signs are likewise forms, i.e., marked differences. They differentiate, following Saussure, the signifier (signifiant) from the signified (signifié)” (GdG 208, my translation). According

\footnotetext{
4 Heider uses the terms Vielheiten ('multitude') and Einheit ('unity'). Despite being a Gestalt theorist, Gestalt as a term does not feature prominently in his work.

5 Prominence is achieved because, in Heider's view, objects-in-the-world as "true entities" force their form upon the medium and the mediated effigy of the object is, in a sense, a "false entity" (Heider 2005 [1926]: 44-45). Because of its unnatural state, it is a recognizable form.
} 
to the general principle of two-sided forms, it should read: "The sign is the form of the difference between sign and signified." However, Luhmann acknowledges the established language use (ZaF 49-50). Nonetheless, the sign is a paradoxical form that includes itself. As both meaning and form are the results of observation and internal processing in a social system, the semiosis is subjected to the theory of operationally closed systems (Esposito 1993: 97). This makes the linguistic sign a property of social systems.

An interpretation of the linguistic sign as a two-sided form shares interesting commonalities with Saussure's original work. For one thing, the formal twosidedness cannot be ignored. As laid out in the Cours de linguistique générale (CLG 99), the sign is composed of the concept and the image acoustique, or generalized as signifié/signifiant. Beyond that and more importantly, however, Saussure and Luhmann stress the dual character of the sign. In the CLG (CLG 99), this is represented by two arrows accompanying the famous ellipsis to the left and right, alluding to the fact that the two sides of the sign "s'appellent l'un l'autre." The two sides are connected "intimement," and uttering the name of the one evokes the other. The dual character of the sign becomes even more obvious when examining Saussure's autographs. The orangery writings and other notes show interesting divergences from the Cours edited by Charles Bally (1865-1947) and Albert Sechehaye (1870-1946). The Third Course suggests that Saussure used empty ellipses in his teaching whenever relating to the systemic value of a sign as a unity and not its inner structure (TC 89, 96, 135). In the Ecrits de linguistique générale (ELG), especially the often cryptic notes item, Saussure devises pictorial approximations to his concept of the sign (ELG Item 3310.5). In contrast to the famous ellipsis of the Cours, he experiments with rectangular forms, but more importantly with ellipses that are structured by a dotted line instead of a continuous one. By this means, the two-sidedness of the sign is reduced and the unity of the sign as a whole is stressed. In addition, there are versions with a horizontal and a vertical dotted line, stressing the idea that the two sides are in fact equals, standing side by side, instead of being hierarchically ordered. There does not exist an ontological primacy of the signifie, since it is not perceived as the denotated reality of the world to which a name is secondarily allocated. In ELG (I.2d) "Principe de dualisme," Saussure rejects the idea that the dualism of the sign lies in its two-sidedness as unity of signifier and signified altogether, but emphasizes the circumstance that the vocal phenomenon is at the same time a form (figure vocale) of physical reality and also the sign in the sense of its full mental representation as unity of signifier and signified. These arguments are lost, if not already in the Cours, in post-WWII structuralism. However, they are of system theoretical relevance, since they can be restated in a paradoxical two-sided form, in which the form of a difference can be taken to be the unity of itself and its unmarked state. For what it's worth, the difference 
between actuality/potentiality also operationalizes the idea of valeur, where the content of an element is not intrinsic but established in the fact that it was chosen for communication from among other options.

The form-analytical interpretation of Saussure's two-sided model of the sign thus seems much more closely related to Saussure's original conception. With both Saussure and Luhmann, it is necessary to contradict the commonly assumed notion of signifiant/signifié as being a simple dichotomy. In this sense, Saussure argues in a more differentiated fashion than some later structuralists (take, e.g., Hjelmslev 1961: 47, who prefers content plane and expression plane) or the prevalent understanding as content and form, with form being a container for extractable meaning. The sign is indeed a dialectically structured, inextricably intertwined duality (rf. Buss 2007). It can be said that a system theoretical approach using Luhmann's derivation of the linguistic sign as a twosided form from Heider's media theory by applying Spencer-Brown's calculus is not only adequate to treat fundamental linguistic questions, but it offers a reliable and elaborated theoretical approach that states the theoretical implications and ramifications more precisely. Just a few of the consequences include the following: The approach instantly dissolves the fundamental criticism of semiotic reference, e.g., by Charles S. Peirce (1839-1914), because the sign is processed as form internally by an operationally closed system and hence bears no reference other than to a constructed internal reality (ZaF 52-54, 60-61; Esposito 1993: 97-98). These signs are non-reductive, too, because they convey their meaning by indicating something specific ("marked state") in contrast to everything that is not indicated, but co-present ("unmarked state"). The semiotic process is also compositional, because forms can serve as a medium for other forms. It has also been recognized, even by critics of Luhmann's approach (e.g., Schiewek 1992: 152), that Luhmann deduces the linguistic sign from a theory of perception and media following Heider, proving the form of the sign as a universal. Most importantly, however - and this will be the theme of the following section - Luhmann's theory gives back a process-dependent, varying and changing character to the linguistic sign. It makes it a diachronic element with a history. Here, another interesting point of contact between Saussure and Luhmann appears: Willems (2011: 35-39) stressed that the linguistic sign in Saussure's semiotic conception can only be understood as a historical unit, which raises the question of which process type describes its history best. As we started this section from the quotation that "linguistic communication processes meaning in the medium of sound," let us now investigate the procedural character of linguistic structure. We will start again with Luhmann (3.5) and then return to Saussure (3.6). 


\subsection{Communication, event, and structure}

Another instance in which Luhmann explicitly refers to Saussure is found, as is so often the case, in a footnote:

[The difference between medium and form] substitutes, or in any case complements, Saussure's difference between "langue" and "parole." It is possible to generalize this difference to the difference between structure and event. But in this case one has to recognize that it is deprived of anything that systems theory accomplishes, namely, to provide an explanation as to how events produce structure and structures steer events. The medium/form difference resides at this interface. It presupposes couplable elementary events (paroles) as well as a necessarily structured language to conduct and vary coupling, moment by moment. (GdG 195 n. 9, my translation)

Luhmann argues in terms of his generalized difference between medium and form in the sense introduced in chapter 2. There are two linguistically relevant aspects, however: First, the relation between structure and event is interpreted by reference to the Saussurean duality of langue and parole and, second, in this relation, the communicative structure exerts a steering capacity over elementary communicative events. The following paragraphs will discuss the system theoretical notions of "structure" and "event" and why they are useful to explain linguistic structure and language change.

Let me illustrate the problem first: Imagine the medium of black printer's ink. As a medium it does not contain any information value, it is formless. Imagine now a cardboard mold in the shape of a letter A. When the mold is laid on a piece of fine hand-made paper and the ink is dispensed over the mold, the result on the paper will be an imprinted form in the shape of the letter A. Let us say, there are a hundred As on paper, some with weaker ink than others, some with minor misprints due to imperfect paper, fingerprints in the ink or moving the mold while printing. Also, the mold may wear off. Every A is an event-like, dynamic formation of an A from the ink-medium, whereas the overall structure of all A-events is generally stable. It is obvious that the reason for the stability is the shape of the mold. But let us assume that the mold has been hidden away by the printer and the only basis for analysis are the hundred As on paper. One way of looking at things is to abstract the commonalities of all As and declare the existence of an essential A. Another way would be to deduce that a mold has been used and to reconstruct the shape of the mold from the event-like forms. Answering the question of what steers the reproduction of the form, in the first case, the abstracted essential A would be seen to be the structure, in the second case the mold. What is a more reasonable ontology? 
Let us now return to the quotation prefatory to this section. It was the decisive novelty of Maturana's and Varela's concept of autopoiesis that the system emanates from a process that self-referentially reproduces the system's elements. As in Bénard's experiment, there is on a local level a dynamic state: the constant reproduction of event-like systemic elements that vanish again at the same time they originate. This constant forming and dissolving is characteristic to dynamic stable processes in general and also to autopoietic systems (GdG 199). The imprinting of a form on a medium is such a procedural event. When Luhmann suggests communication to be an autopoietic process, a communication as a temporalized event actualizes forms (phonemes, morphemes, phrases) imprinted in an unsorted array of medial elements. As utterances, these forms dissolve again into their medium after being communicated. According to Luhmann, this definition of event and form can expand Saussure's concept of parole system theoretically. On a global level, in contrast, a stable structure can be observed. For linguistic structure, the observable grammatical orderliness of linguistic elements can be related to Saussure's notion of langue. Luhmann's reference to Saussure highlights two significant linguistic points of discussion: First, the term langue immediately evokes its double meaning as the abstracted language system and the elements-in-relations structure. Therefore, it is necessary to show how system and structure can be disentangled. Second, the opposition structure/event and langue/parole raises the problem of abstraction and instantiation as discussed by Hutton (1990), who showed, based on a discussion of the type/token relation, that the crucial explanandum in linguistics is the ontological state of linguistic abstraction and subsequently the nature of linguistic knowledge. This subject will therefore be included in the further discussion.

When we said above that, on a global level, a stable structure can be observed, this was a common abbreviation. What can be observed is the frequent reappearance of similarly shaped event-like forms. The problem with this is that a system's structure cannot be defined on the basis of dynamic elements which continuously perish and reappear. We need an alternative definition of structure. From a procedural perspective, the appearance of a form is an event-like selection by the system. In a succession of similar events, it is the selection itself that seems constant (SS 384). So, the question is rather: What regulates the selections? Here, Luhmann allows for the re-entry of observation by the system into its process. Whenever a new communication is due, the current state of the system is the result of all its past operations. This state determines any further selection (GdG 94). Looking backwards, one could say that the system observes and evaluates the past selections. Looking forward, in turn, it makes the result of this observation available to the system by calculating a possibility space for 
further selections. As a result, the system's own history limits the selection of future events, while every single selective event becomes part of the system's history. The possibility space and the actualized selections thus relate in a circular manner.

$<$ system history $\circlearrowright$ selection>

This is an immaterial, dynamic mold: the structure of social systems. Structures of social systems are expectancy structures (Erwartungsstrukturen; SS 158, 398; WdG 136). They are the conditions that license the alignment of elements (GdG 430) and should be distinguished from the reproductive process itself (SS 393). They exert a steering capacity on events. Language is an expectancy structure in that sense. But how does it come about?

It is necessary to point out that "expectancy structure" does not mean the expectations of individual cognitive systems, but an emergent property of social systems. To Luhmann, it is an illegitimate reduction to claim that biological and cognitive states correspond to communicative events (SS 346). In much the same sense as neural activity gives rise to the emergent phenomenon of cognition, the co-presence of individuals gives rise to a social system. Let us for a moment assume the co-presence of cognitive systems in a pre-cultural state, with no conventionalized signs for communication at their disposal. As operationally closed systems, they operate in their respective environment and their communications are mutually contingent events (SS 148). They need to reveal the meaning of their proto-communications from the reactions to their own communicative offers. If a subsequent communication is consistent with my own communication, the communicative means that have been deployed seem adequate to the meaning that had to be processed. It is then very likely that I will draw on my communicative success and use a similar form of communication to convey similar meaning in a similar context, because I expect the same result to occur again - as will anybody else who observes the success of my communication. To process meaning, any selection of further communications then operates under a projection of what one expects the other to expect from oneself. These 'expectations of expectations' (Erwartungserwartungen, SS 411-417) are no longer subject to individuals. ${ }^{6}$ From a perspective of first-order observation, the interlocutors are not free to choose whatever communication they like. I need to say cinema when I mean “cinema.” I need to use first person plural if I want all

6 Here, Luhmann exceeds Parsons' original theory. Compare Parsons' "set of complementary expectations" (Parsons et al. 1951: 11) with SS 158 and 411-417; see SS 396 for a general discussion of "expectation" as a concept in sociology. 
other members of the group to follow my suggestion to go there. I need to use question syntax if I want an explicit answer. From a perspective of second-order observation, communication steers itself by feeding the result of its observation again into communication. A lexical item, a morphological form, a syntactical structure are expectable. Communication as a self-contained process accrues. Expectancy structures reduce complexity and contingency in communication.

In contrast to the hypothesized pre-cultural state sketched out above, communicative means and expectations of present-day communication have been "tested" and "approved" many times. In the course of events, the social system produced and maintained a highly elaborated set of discrete and independent forms: Symbolic generalizations arose that symbolize mutual expectations in communication (SS 416, 426). Cultural symbols ${ }^{7}$ of all sorts have been conventionalized to make meaning generally and easily available to communication (GdG 318). Symbolic generalization is a case of a very general cybernetic principle: The establishment of order through repetition. In cybernetics, it has been phrased with all its epistemological and ontological implications by Heinz von Foerster (1911-2002). According to him, and in explicit reference to Luhmann (Foerster 1993), communication is a recursive process that creates the entities it communicates about in a self-referential manner: It feeds the results of its process continuously into the very same process and thus stabilizes the results. Von Foerster applies the term Eigenvalues for these entities. Luhmann, again in explicit reference to von Foerster, arranges this principle according to form analysis and self-reference: The repetitive distinction consolidates the marked state and the form of a difference by two means: First, every use of a form in communication makes its later re-use in similar communicative contexts more likely (condensation). Second, since communicative contexts will always differ in detail, the meaning of a form increasingly acquires additional facets of meaning and thus generalizes (confirmation; GdG 409; WdG 108, 311-312). The circular relation <system history $\circlearrowright$ selection> is therefore not redundant, but as an Eigenvalue operation a specific process type of structure formation: self-referential, time-dependent, based on repetition cycles, and hence frequency-based. Luhmann lays out this formation of symbolic entities for meaning, but it follows from the general difference between form/meaning that also the form of the sign is processed in that fashion (cf. section 2). It is, to my eyes, very tempting to adopt this theoretical framework for a theory of language change, especially as Luhmann is quite clear about the prominent

7 The restrictions to certain selections form a collectively shared model of situations that could be called the "culture" of a society, and the symbols are their cultural achievements; cf. Parsons' "shared symbolic system" (Parsons et al. 1951: 16). 
role of language among other cultural symbols such as money, power, knowledge, etc.: Language as a form of transmission is particularly noticeable; its semiotic character forces the observer to perceive things. Words and grammatical structures allow references to past and prospective actualizations of meaning; they guarantee align-ability as well as condition further selections like no other generalized form of communication. Luhmann terms this quality the "exclusiveness of language" (GdG 442). ${ }^{8}$

The following four points will illustrate how language change could be viewed differently when applying such an approach.

\subsubsection{Structure}

It is now possible to define "system" and "structure" as discrete entities within one theoretical framework. One has to conclude that language itself does not have its own operational mode; it has to be carried out within a system's process: communication. Its systematic shape is the result of it being produced, used and developed by a system (GdG 112), instead of being a system itself. In the case of language as a communicative medium, social systems are the processing unit; the autopoietic process type is communication, and language is a structure of social systems. It seems somewhat counter-intuitive that language cannot be regarded as a system when seen from a contemporary system theoretical point of view. This is exactly the consequence to be drawn from the last 120-odd years of development in systems theory. This separation, however, strengthens the notion of grammatical structure, which becomes a descriptive term for a dynamic-stable expectancy structure without any claim to autonomy or self-regulation.

\subsubsection{Dynamic structure}

It has always been tacitly assumed that any synchronic dissection of a given linguistic structure is a snap-shot of a dynamic structure. But whereas the inherent logic of the syntagmatic/paradigmatic method of analysis forces a static picture of language structures, the notion of structure in autopoietic processes allows for a theoretical integration of event and structure. In contrast

8 The submission of language under the general theory of symbolic generalization has been criticized (Künzler 1987; Schiewek 1992). But a unified theoretical approach can also be desirable (cf. Luhmann 2009). 
to current usage-based models, however, grammatical structure is not purely epiphenomenal to its usage. As the mechanism <system history $U$ selection> indicates, usage (as event-like form) and structure (as expectancy structure) are intertwined by the process of communication, i.e., the system type (autopoietic, meaning-constituting systems; cf. Section 2.2) determines the structure more than the mere events. ${ }^{9}$

\subsubsection{Structure formation and change}

As a consequence of a dynamicalized notion of "structure," synchrony and diachrony no longer need to be perceived as "two radically different approaches" (CGL 79), but as intertwined. When a change in communicative events can be observed, it is determined by the constitutive mechanism <system history $U$ selection $>$ that varied selections must have been absorbed into the system's history and changed the possibility space for further selections. How is that possible? Social systems have learnt to deal with contingency (SS 414). They attach procedural importance to events that violate the expectancy structure. Therefore, the information value of a novelty does not lie in its form or meaning, but in its divergence from expectations. The system does not need to understand the nature of the perturbation (SS 397), which is a means of reducing the erratic complexity and destructive potentials of communicative events. Luhmann specifies that a system exclusively reacts in one of two ways (SS 436): A violation of expectations can lead to a refinement of the expectations when the selection offers alloy into system history, i.e., they lead to further communications that repeat the varied events. Or, the system absorbs the violation by holding on to its expectations and repeats the events in their original form. In the prior case, there would be structural change, in the latter there would not. Take as an example the violations of expectations which youth languages bring into standard language. Certain novelties diffuse from one social system to the other while most peculiarities die away. It is the structure of a system that introduces the degrees of freedom to advance structure formation. Observation projects expectations for further selections, and selection offers that exceed the possibility space will be tolerated or refuted. Between these two conditions there is always leeway, a margin for change. Luhmann himself uses the metaphor of a

9 See for the distinction between "usage fundamentalism" and mere usage-based approaches Harder (2010: 181-182); In Harder's own model, "structure” is not purely epiphenomenal either, but takes a stronger (langue-like) position (2010: Chs. 6 and 7); It is a model of "language in society" (Harder 2010: 444) based on cognition and action. 
canal, of structures channeling the events (GdG 431). Like this, contingent selections can exploit the leeway over time and changes can accumulate. It is thus reasonable to conclude that the explanatory interest of Historical Linguistics does not lie in the manifold of structural variation alone, but the enabling or constraining conditions of communicative alignment.

\subsubsection{Teleological, causal, and functional explanations}

As an exclusive mode of explanation, teleological, causal, or functional models of language change are deficient given the complex fabric of factors that govern language change. It is therefore the main interest of all recent models of language change to provide a specific process type in which these modes combine. They seek to explain language change as non-erratic but also without teleology and predictability. The process type “evolution” (Croft 1996, 2000; Ritt 2004), for example, combines an element of contingency for the causes and occurrences of altered ("mutated") elements with a causal process of selection and (re-)stabilization. Keller's invisible hand process (1990) combines an element of individual decision-making and social regulation with a mathematical effect of accumulation to produce unintended results. And Lass' programmatic assessment of dynamical systems and attractors of change (1997) avoids ontological pitfalls and provides stochastic modelling to elicit procedural types of change. In the case of social systems and the autopoietic process type "communication," the mode of closed self-referential reproduction is not causal, final or functional. When looking at an individual communication, it is a result of a selection from a possibility space. It is therefore at once contingent, determined, and undetermined: contingent, as its position within the possibility space could not be predicted; determined in its actuality and information value, because it is an episode of a meaningful communication; and undetermined in its potential alignment, because elements of communication do not specify their exact follow-up communication (SS 80). The overall process of communication is therefore in the best cybernetic understanding self-regulatory in nature (kybernetike tekhne 'the art of the steersman'!). The conception of autopoietic processing introduces a model of change that distances itself from teleology and a too-narrow sense of causality, but relies on a model of introduction and conditioning of degrees of freedom and of opening and limiting leeway for selection (Baecker 2005: 8-9). It combines undetermined potentials of development with a lack of arbitrariness. It is thus an attractive model for a nondeterminist view of language change. In this sense, Luhmann's contingency of events and the limiting effects of the structures on the selection of events are the functional homologues to Saussure's arbitrariness and conventionality of the sign. 
The cybernetic nature of the process also guards against overly direct functionalism, where function stands in a causal relationship to structure. Language does not evolve teleologically to enable the mutual exchange of information or the self-representation of individuals, nor is language a set of norms. Language rather evolves to provide flexible and operable forms to enable the autonomous operational mode of social systems beyond cognitive processing (GdG 220). It is, in other words, part of the social order. This systemic formulation is entirely different from models of action-based emergence of social order. These argue with agents, their natural and self-determined needs, and with conformity, co-ordination, or reciprocity of perspectives in the domain of individuals. Also Parsons argues with consensual normative orientation in a "shared symbolic system" (see SS 148-177 for discussion). To social systems, however, the motives of individuals remain inaccessible under all circumstances, which renders them useless as a definition of social order.

\subsection{Luhmann, Saussure, and a social ontology of language}

The application of the current systems theory does not only enable a procedural perspective on signs, language, and language change. It also has a strong ontological implication. Maturana spelled out the corollary for cognition under the term "ontology of observing” (Maturana 1988). Cognition is seen as the selfpreserving mental process of an individual, and the cognitive system as processing unit is understood as an operationally closed entity that is capable of selfobservation. Cognitive systems use observation (perception and internal processing) to construct a meaningful self-reinforcing internal effigy of the world and the self. Since internal construal is the only possibility for individuals to perceive the world, these inner representations can be said to become "real." Following the principle of autopoiesis, the same must hold true for social systems. Their observations, re-entering their processes, create their social realities. The Eigenvalues of communication, which in our definition include grammatical structures, are from a system's own point of view facts - we might say social facts. In the context of Luhmann's theory, I use this term loosely. It is otherwise not justifiable but useful to make a serious point with regard to Saussure. When discussing Niklas Luhmann's system theoretical reception of Saussure's terminological pairs signifiant/signifié and langue/parole, fundamental differences to Saussure's early structuralist position become obvious. It seems that a modern system theoretical approach to language would concentrate on the term structure, rather than system. But it is necessary to consider the system, the processing unit, too. Let me illustrate why. 
Towards the end of the nineteenth century, the ontological implications of the term "organism" in linguistics became a burden, primarily language as having a life of its own and the notion of life cycles with its in-built teleology (Albrecht 2000: 227-233), partly also the congruency with races whenever historical comparative linguistics was read as the historiography of Indo-European societies (and sometimes still is: for criticism, Hutton 2013). The notion of "system" provided a timely substitution, discarding the unwanted implications of the older term, whereas it seemed to preserve all the useful connotations - a structured whole as an autonomous entity that serves as the object of a discipline; an internal complexity with emphasis on every individual element as interdependent on the whole. Systemic thinking, after all, conformed to the general posture of positivism at the time. However, systems theory was itself under formation at the time. The developmental stage available was strongly oriented towards the structural concept of systems. It focused on elements-in-relations and could therefore not continue other essential elements of the organism metaphor, namely, the interaction of organisms with their environment and the observation of the emergence, variation, and differentiation of organisms and species. ${ }^{10}$ The reciprocity of the terms can still be observed in the CLG. Passages such as the following indicate that the notion of "system" continues the original interpretation of structured and organized entities while at the same time disavowing the fact that languages actually are natural organisms. The translation by Roy Harris emphasizes this very point. "A language system, as distinct from speech, is an object that may be studied independently. Dead languages are no longer spoken, but we can perfectly well acquaint ourselves with their linguistic structure [leur organisme linguistique]" (CGL 14 [CLG 31]). And a little later, this: "Our definition of a language assumes that we disregard everything which does not belong to its structure as a system [à son organisme, à son système]...” (CGL 21 [CLG 40]). Mounin (1975 [1972]: 88-89) counts 138 appearances of système in CLG. By

10 The term "organism" itself was originally not used in contrast but in an articulate proximity to terms like edifice, mechanism, engine, and the like. It inherited its semantic breadth from its etymological root ö $\rho \alpha \alpha v o v$ 'technical tool, instrument, sensory organ, body part,' and was often a term of classification denoting structured and organised entities. First in the course of the nineteenth century it was narrowed to its biological meaning. On the one hand, organisms have a history and a development, which made the term attractive to nineteenth-century historicism. The term could capture both the nature of individual organisms (Kant Critique of Judgement: $\S 64)$ and, with Lamarck and Darwin, of species. On the other hand, “organism” emphasized the autonomy and ability to interact of the objects under investigation. Cf. Köller (2012: 266-271) and Ballauf (1984: 1317-1326, 1330-1336). At the latest, August Schleicher turned the metaphorical aid of understanding into an ontological claim: Languages are natural organisms (Schleicher 1873 [1863]: 6). 
contrast, structure appears three times and is actually never used in the sense expected from structuralism. Rather forme(!) seems to capture the structuralist notion of "structure." Organisme only marginally appears in contexts like the ones above. It is my impression that the same holds true for the notes. ${ }^{11}$ Two things should be stressed:

First, system is the term that expresses internal structuredness. It was first the post-WWII structuralism that elevated structure to its prominent position. As Gadet (1989) showed, the CLG received a rather modest echo after publication, but bloomed in reprints and translations after 1960, in the context of the en vogue structuralism in other disciplines. Then, a whole generation read the CLG as their founding text (Dosse 1996: 80). Somewhere along the way, between Saussure's original ideas, the compilation of the Cours and post-WWII structuralism, the observation of orderliness in language turned again into an ontological assertion about language. System could no longer serve as the term that expressed orderliness but had to carry the ontological weight of the scientific object, whereas structure stepped into its shoes without being properly redefined. Now, structure and system recursively specified one another: The fabric of elements-in-relations is a system. ${ }^{12}$ Where the organism account added an internal dynamics, interaction with the environment and a developmental history, the system approach had only the elements-in-relations as self-definition and left the blind spots dynamics/ stability, internal and external function, and change.

Second, system as an amendment for organism and not (yet) identical to structure allows for a wider perspective on language than an elements-in-relations analysis. Without iterating the discussion about the degree of theoretical continuity or discontinuity in Saussure's writings and teaching or the CLG, ${ }^{13}$ it is safe to say that outcasts for a new linguistics being published around the turn of the century generally promoted a much wider conception of language: Paul's theory of principles in the context of the Neogrammarian school (cf. "das wahre Objekt für den Sprachforscher,” 1960 [1880]: §§11-20), von Gabelentz’ idealistic linguistics (cf. "drei Betrachtungsweisen, die unsere Wissenschaft verlangt"

11 According to the index of ELG, organisme appears on ten pages - with the exception of ELG 197, it is always met with a critical stance; structure only three times (and exclusively as the sound or morphological structure of individual items), system, by contrast, on forty-six pages; interestingly, ordre achieves an even higher count with seventy-one pages.

12 Also "structure" and "function" converge: "une structure est par définition un tissu de dépendances ou de fonctions" (Hjelmslev 1942: 31). The language-internal position of an elementin-relations is its contribution to the holistic systemic structure. The Systemzusammenhang is construed relating to the internal operating and not the external behavior of the system. This annihilates any external functionalism and blurs the difference between structure and system additionally. 13 Cf. mainly Koerner (1973); Coseriu (1977); Scheerer (1980: 120-151); Wunderli (1981). 
[1901: 10]), but also Saussure's positivism. His vision of a synchronic descriptive linguistics contained more than an inventory of grammatical form. For one thing, the CLG is divided into the main sections on synchronic, diachronic, and geographical linguistics. But beyond that, the presentation contains chapters, paragraphs, and passages that relate the physical and mental speaker, language as a social phenomenon, writing, physiological phonetics, acquisition, psychology, ethnology, and other perspectives. Saussure makes the points-duvue argument: “... it is the viewpoint adopted which creates the object” (CGL 8). Every viewpoint changes the image of the object, and the object in its entirety is only perceived when its bearing is taken from several viewpoints. The viewpoint argument has, of course, one decisive drawback: It renders a theoretical (and then methodical) integration impossible when every viewpoint is exerted as a solitary discipline (CGL 23), like physiological phonetics (CGL 32), research on writing (CGL 24), or ethnology (CGL 222). Saussure grounded his distinction of langue/parole on the necessity of scientific rationalization. Linguistics was only possible as a science of the langue. This way, the viewpoint argument mainly served the demarcation and the autonomy of linguistics as a discipline. ${ }^{14}$ PostWWII structuralists, fostering autonomy, concentrated on the restrictive analysis of value-elements derived by analysis of their syntagmatic and paradigmatic relations. They regarded it an achievement to leave the conditions of the structure's appearance and processability unobserved. ${ }^{15}$ So, paradoxically, the aspiration to further objectivity, homogeneity and autonomy in linguistics has distanced the grammatical system from other viewpoints.

Modern systems theory promises theoretical integration. As a general systems theory, it is a unifying structural science (Strukturwissenschaft) in the sense of von Weizsäcker (1971). As a general theory of autopoietic systems, it is a unified approach to physical life, cognition and social systems. As the Theory of Social Systems, it is a theory of structure formation in communication. The same principles in varying degrees of specificity can thus be applied to all aspects of language, from physiology and cognition to linguistic structure.

Dosse (1996: 89) argues that Saussure's distinction of langue/parole unnecessarily binds together two analytical dimensions: langue/parole as constructed/ given (classé/donné ELG 19-20) is justifiable, whereas langue/parole as system/ performance (système/execution ELG 36-37) is not, especially as it entails further dimensions such as necessary/contingent (essentiel/accidentiel CLG 30) and

\footnotetext{
14 "The aims of linguistics will be: ... to delimit and define linguistics itself." (CGL 6).

15 Dosse (1996: 82-83) quotes a personal conversation with Martinet, who stated that Saussure missed the point in explaining the linguistic phenomenon in itself. It was first the Prague school that achieved that goal.
} 
especially social/individual (social/individuel ELG 299/CLG 30). With Luhmann's theory, it becomes possible to dissolve that matter: (i) constructed/given: The constructed amalgamates with the given already on the procedural level of the object itself. Social systems observe their communications and an expectancy structure arises. In terms of an ontology of observing, it can be said that this structure exists in social systems. The social system "linguistics," extracting the grammatical structure from an observation of communicative events, conducts second-order observation. (ii) system/performance: Language is analyzed as a structure of social systems, which as a dynamic-stable expectancy structure is bound to its use but not identical to it. (iii) necessary/contingent: As selection from a possibility space, every communication is both contingent, determined and undetermined. Static necessity is excluded from dynamic-stable structures. In addition, the contingency of events and the limiting effects of the structures on the selection of events are the functional equivalent of conventionalization. (iv) social/individual: Communication is construed as the self-reproductive process of social systems. The forms of communicative events (parole) are therefore already social in nature and the individuals are their conditions of possibility. ${ }^{16}$

A theoretical integration of (iv) seems to be the most significant accomplishment; let me illustrate the direction and potential. Saussure states in several passages that language is a social fact. This indicates a certain acquaintance with Durkheim's sociology, either as tacit knowledge or through private reading. ${ }^{17}$ The earliest reference, a note (early 1890s), reads:

Characteristics of language. Language is always being considered within the human individual, a false viewpoint. Nature gives us man ready made for articulate language [le langage articulé], but not actually in possession of it. The language system [la langue] is a social fact [fait social]... Langue as a social phenomenon [fait social] can be compared with customs [us et coutumes] (constitution, law, habit, etc.)...” (WGL 120 [ELG 178])

In the notes for the second course of 1908-1909, the second duality "individual/ mass" is mentioned: "Langue, which as such is unrelated to the existing human mass, is inseparably linked to the human mass. Other forms: Langue is social, or

16 Also Cognitive Linguistics realised that the social reality of language is under-theorised in their models; cf. for an overview on the "on-going social turn" of Cognitive Linguistics, Harder (2010: 58-102); Geeraerts (2005: 164) on the incorporation of social variation; likewise the "Cognitive Sociolinguistics" of Kristiansen and Dirven (2008) or the "Social Cognitive Linguistics" of Croft (2009); Tummers et al. (2005) on the state of real-usage data in corpora; Verhagen (2005) on intersubjective coordination. For a detailed comparison of cognitive and social approaches to usage-based models, see Zeige (2014).

17 Cf. Durkheim (1956 [1895]); for the pros and cons, see Doroszewski (1933), Hiersche (1972), Washabaugh (1974), Koerner (1973: 45-66), Bierbach (1978). 
else does not exist. If the language system is to become established in an individual's mind, it must first be accepted by the community" (WGL 133-141). And the langue is explained thus: "Langue is established socially and does not depend on the individual” (WGL 241-246). In CLG, finally, possibly the most prominent passage among many is found amidst the recapitulation of the properties of langue: "It is the social part of language, external to the individual... It exists only by virtue of a kind of contract agreed between the members of a community" (CGL14). Some terms of these quotations need to be laid out.

\subsubsection{Individual/mass}

In contrast to the later structuralist position, where mainly the viewpoint of the language system as an abstract and autonomous entity remained, these passages indicate a regulated relationship with both the individual and the speech community. Its importance is also indicated by its rank: The duality individual/ mass in the lecture notes is mentioned second, right after the dual character of the linguistic sign as the first and before langue/parole as the third duality (in contrast to the Cours). The interdependency of the language system with the single individual and the speaking mass is also reflected in the passage on the speech circuit (CGL 11-15), where the mutual physical and psychological abilities of the individuals only are "language in embryo" and one must "proceed to consider the social phenomenon [fait social]... for the language is never complete in any single individual, but exists perfectly only in the collectivity [la mass]" (CGL 13 [CLG 29-30]). The position on operationally closed and structurally coupled cognitive and social systems here provides a useful theoretical framework which allows the nature of individual linguistic knowledge to vary from a system's expectancy structure or, indeed, to be quite different from it.

\subsubsection{Psychology/sociology}

The fact that the language system as such does not lie within the individual, that the individual has to inherit a representation of it from the speech community, and that it is a mass phenomenon seems to stand in contrast to quotations like the following: "In the final analysis, where languages are concerned everything has its psychological aspect..." (CGL 7). However, it is necessary to understand that the underlying psychology is that of social psychology (CGL 7). It is a supraindividual psychology, where all experience and behavior is conditioned by social facts towards which the individual remains passive, due to "the 
individual's receptive and co-ordinating faculties" (CGL 13). It is hence not a contradiction that the language system is represented in the mind of individuals, but the individuals do not exert a steering capacity on it. Bierbach (1978: 43) observed that the langue, defined in this way, shares many properties of Durkheim's "représentations collectives": emergent entities with their own properties not reducible to the individual's faculties, defying the individual's control (but not its exertion). In sociology, the position on operationally closed and structurally coupled cognitive and social systems has outdated Durkheim's social psychology (NB the link from Durkheim to Parsons to Luhmann).

\subsubsection{Customs, contract}

On the one hand, the terms used to characterize the social nature of language social fact, social product (CGL 9), social institution (CGL 15), collective habit and convention (CGL 68) - bear witness to a general sociological orientation, strengthening the idea that language is an inter-individually conventionalized symbolic system just like others ("constitution, law, habit, etc."). On the other hand, it is recognized that language has different properties than other social achievements (WGL 120-121; CGL 71-74, 76-78): Like no other social phenomenon, language corresponds to a "special organ" in the individual; its communicative purpose makes language a prerequisite for every society; people are to a larger extent unaware of the laws that govern language than other social institutions; and the degree of arbitrariness in the symbols, the complexity of language systems, and the extent of its everyday use in a community are incomparable to any other social symbolic system. Language as a set of rules is rather imposed upon a community than freely agreed to, and as an inheritance from the past it is rather invariable when compared to other social institutions. "It is simply the most important of such systems" (CGL 15). One can sum up that language as a system of symbolic forms stands out among cultural achievements, which mirrors Luhmann's position on the exclusiveness of language (cf. section 3).

\subsubsection{Semiology}

The CGL $(15-17,68)$ sketches "semiology" as the study of a class of systems that are independent from the will of individuals and communities, that are based upon the arbitrary nature of the sign and on customs, and that are accepted in a community as a means of expression. Semiology is a general approach to symbolic systems in social life, with language as its most important object of study: "It 
is therefore possible to perceive of a science which studies the role of signs as part of social life. It would be part of social psychology, and hence of general psychology" (CGL15). After having waived social psychology and the notion of language as an autonomous system, it is still possible to emphasize the semiological relevance of language as part of the study of symbolical generalization.

\subsubsection{Social change, language change}

The Cours states that a characteristic of any social institution is a "balance between the tradition handed down and society's freedom of action” (CGL 72). But for the reasons mentioned under Section 3.6.3, the CGL concludes that in language in total "the historical transmission is the overriding factor, to the point of excluding the possibility of any general or sudden linguistic change” (CGL 72). Structural stability, in other words, is made a function of time (CGL 74), and hence a procedural component is introduced, by which the "[c]ontinuity with the past constantly restricts freedom of choice" (CGL 74). These statements remain unconnected given the structural analysis of the langue and the law-based diachrony proposed in their respective chapters. It is obvious that the two cannot be brought together: how the undisputable linguistic change is based on a predominantly permanent continuation through time. But it likewise cannot be ignored that the "past" (or should one say "history"?) and "time" start to occupy the same theoretical position from which "nature" and "organism" had newly been eradicated. If one factors out the generally suspicious concepts of equilibria and teleology in mechanistic elements-in-relations systems (cf. Martinet's chaine de traction/propulsion [1955]), it needs a dynamic-stable conception of structure to dissolve this matter, characterized above as the establishment of a possibility space and contingent selection events in social systems. But then linguistic structural change derives from the properties of the systemic process of communication and not from the properties of an elements-in-relations structure or their external functions. In such a model, the social facts are literally done or made (factum!) in the system's process.

Consequently, 3.6.1 and 3.6.2 disentangle linguistic structure from the individual's language faculty, but the langue's state as a conventionalized symbolic system (3.6.3. and 3.6.4) also robs it of any naturalness. Although recognizing the reproductive component of social structures, the dynamic component is excluded for theoretical reasons (3.6.5). The linguistic theory of the Cours thus leaves the emergence of the language system unexplained and assumes it a priori because a system internal viewpoint on language structure and a social fact position on language as a communicative medium cannot be specified within the structural concept of systems. Early on, it was therefore remarked that the produit social 
remains a product without a process of production (Baudry 1968: 361). Saussure, "le structuraliste sans le savoir” (Mounin 1971), proposed a complex enterprise, but was well aware of the methodological challenge. The whole CLG chapter on the "internal duality of all sciences concerned with values" (CGL 79-81) is a demonstration of the reason why the structural method blindfolds linguistics towards its own rightful claim that linguistic structure is at the same time a systemic entity and a social entity that depends on the exertion in time within the social sphere. Thus, as Koerner (1973: 53) stressed, the fait social dimension never constituted an integral part of Saussure's theory. It is therefore necessary to argue in contrast to analyses like Bierbach (1978: 3) that the reason for the theoretical disintegration of different viewpoints in Saussure's works and his mathematical, counting and structural approach to langue lies not in his adoption of the ideological momentum of Durkheim's positivist sociology in itself. It lies in the system theoretical model with which it was exerted, and the fact that the structural concept of systems simply does not allow for a unified theory. It needs an ontologically rich systems theory to fully integrate the social character of language. It is necessary to surmount the structural concept of systems, as well as the psychologie sociale. A state-of-the-art sociological systems theory represents both. By applying Luhmann's Theory of Social Systems, the faits sociaux are substituted by structures of social systems. If language change is analyzed as the formation, maintenance, and development of a specific part of the symbolically generalized structure of a social system - something that the notion of "semiology" always included - it would be possible to exceed the structuralist notion of linguistic structure by far, yet still be in line with the universal but theoretically disintegrated conception in Saussure's notes and the CLG. The notion of Eigenvalues as dynamic-stable entities of observation would also eradicate the simplistic notion that a social fact is some sort of mathematical mean value operation (CGL 13 [une sorte de moyenne (ELG 29)]). Generally, language change is part of the structural change of social systems and hence "social change" (for the concept, see SS 470).

\section{Conclusion and outlook: Implementation}

In summary, we looked at an interesting case of the repeated transfer of an idea in the history of science. Saussurean linguistics informed an understanding of society as communicative systems in modern sociology, whereas Luhmann's conception of language as a symbolic structure of social systems dissolves some problems of classical structuralist linguistics, like the equation of "structure" and "system" (Albrecht 2000: 233), or the static character of the linguistic sign. It was shown for the cases of the linguistic sign and the relation of structure and event how Luhmann explicitly derives his position from a critical 
reception of Saussure. The system theoretical translation of these notions is in part even closer to the original position of Saussure than to those in classical structuralism. It was claimed that language arises as a dynamic-stable structure of social systems from a frequent reproduction of symbolic generalizations in an autopoietic process of communication. This reproduction is steered by the limitations and degrees of freedom introduced by a calculus of self-observation in social systems. The fact that Luhmann's theory is composed with a certain inner complexity can hardly serve as an argument against it. Form-analysis, a cybernetically inspired understanding of communication, the form/medium difference and the linguistic sign as form seamlessly combine to explain the motility of linguistic signs and to motivate the potential for linguistic change. For semiotics, this position emphasizes the relevance of language as part of the study of symbolical generalization in general. In Luhmann's view, language is a specific part of the symbolically generalized structure of a social system, a position drawing nearer to a universal notion of "semiology." Linguistics, in particular, would gain a dynamic perspective on linguistic structure that includes variability and optionality, with structure not being epiphenomenal to its usage. It is possible to construe a new social ontology on the basis of Luhmann's theory. Finally, as a contribution of linguistics to sociology, linguistics would specify the prominent role of language in Luhmann's social theory ("exclusiveness of language").

In the current state of the debate, the application of systems theory to language change is primarily a meta-level analysis that allows a re-framing of our understanding of the processes that shape linguistic structures. To conclude this article, I find it necessary to stress that there is a realistic chance that the theoretical framework can actually feed into a model of linguistic description. It is self-evident that within a newly proposed framework, all the hands-on work has yet to be done. Likewise, it becomes obvious that a complex investigation into the processing of linguistic structure in social systems cannot be the task for a single individual. Furthermore, I am convinced that linguistic methodology is evolving so rapidly and is so multifaceted that there is no room for scientific revolutions and re-invention of the wheel connected to any new framework, but rather a specific combination of established methods and their purposive development. In this sense, Zeige (2011: 197-261) discusses the combined methodological approach to language change and social systems in more detail. Let me point out some general aspects regarding how a position on language as a structure of social systems can be corroborated. Three perspectives must conjoin: a macro-level computation, a micro-level observation, and research on the environment of communication in a system theoretical sense. 


\subsection{Macro-level}

On the macro-level, the proposed model needs to be developed and tested on the basis of large-scale corpus analysis, accompanied by a convenient means of visualization. There is no reasonable argument with which to question the established corpus linguistic methodology. But what exactly is it that we see in corpus data? From a cognitive perspective, corpus data seem to be the lifeless residue of complex cognitive activity, something for which the term "offline data" is common (cf. Heylen et al. 2008: 101). The inclusion of a sociological theory of communication supplies us, however, with an alternative approach: It is adequate to assume that an analysis of corpus data - which are, in fact, collated from real-life communicative events - provides access to the dynamicstable linguistic macro-structure of social systems. Annotated corpus data are, in the sense of the difference between form and medium, form. It is the ontological artifice of corpus linguistics to deduce the systemic structures from a secondorder observation of these forms.

To this end, an analysis of grammatical values in dynamical systems will, in the long run, combine more closely with contextual data: (a) Dynamical systems. As for the dynamic stability of structures, it will be a matter of trial and error whether mathematical, statistical, information technological, cybernetic or other models yield the best results weighted to the demands of available corpus data, applicability, and clarity of variational and developmental patterns. Frequency distribution, reproduction cycles, and mutation rates are one perspective from which to look at things (Landsbergen et al. 2010). Cybernetic models of systemic Eigenbehavior might be another. The hierarchical organization of form/medium may point towards Construction Grammar, the procedural character of structure formation to Fluid Construction Grammar in particular (Steels 2011). With its cybernetic background in artificial intelligence and computational simulation, such a model is intrinsically akin to a system theoretical approach as laid out here. Construction Grammar in general is increasingly used as a tool for diachronic analysis (Fried 2013: 419-421). It also has the best potential to discard its own history in cognitive linguistics and acquisition research and to become a universal descriptive tool of linguistic structures. Constructions as processed real-world language data do not necessarily have to reflect a cognitive reality. In its orientation towards conventional symbolic units and language-specific grammar, Radical Construction Grammar is an exponent for that (Croft 2001). Theoretical and methodological views of these schools may recombine. (b) Contextualised dynamical systems. It has been pointed out that every fullscale corpus analysis automatically forces one to deal with inherent variation (Geeraerts and Kristiansen 2014). A corpus-based deduction of systemic 
structures must take into account the full breadth of variation. As corpus architecture increasingly contains detailed metadata on geographical space, social strata, or speaker groups, these can serve as approximations to identify single or interlaced social systems. For example, the Rhenish Fan is known for its village-to-village progression of the sound changes of the High German consonant shift. Beyond that, certain dialects like the local vernacular of Wermelskirchen have received wider attention due to their behavior of blending shifted and unshifted forms within single paradigms (Venema 1997; Davis 2008). There are also "relic words" that remain unshifted in their whole paradigm, although analogous structural positions generally are shifted in the same area. These cases indicate that every single form is processed (as an Eigenvalue) according to its communicative align-ability and not according to the structural properties of the element or abstracted laws of form. As for variables like age, sex, or social stratum, it should be noted that sociometric data reflect the individual's abstracted position as an instance of communication. The correlation between linguistic variables and the sociometric properties of an individual or a societal subgroup must be seen as epiphenomenal to the communicative structure of the system. Structured heterogeniety (Weinreich et al. 1968: 150-151) is not reducible to individuals. Corpus data should therefore be analyzed as text networks or similar constructs.

\subsection{Micro/macro link}

In addition to these macro structures, a sufficient methodology of communicative structure formation must capture the micro/macro link: the path of a novelty from its first appearance as an irritation to communication to its propagation in the macro structure. Lower aggregated social systems (face-to-face interactions and small social groups of proximate physical presence) display a higher degree of innovativeness (GdG 478-479), mostly due to irritations from psychological systems. They provide the frame for the study of the entrance and immediate continuation or rejection of novelties in communication. Higher aggregated social systems, in contrast, usually work off irritations introduced by other stable social systems and are hence the locus for the study of diffusional patterns. To this end, social network analysis can become an instrument of system theoretical research. Although "network" is not a concept used in the Theory of Social Systems, network analysis can be used as a method to quantify the social system as the amount, range, and intensity of a recursive network of communications (Baraldi et al. 1999: 91). The perspective of social systems as networks of communications would substitute the idea of speaker groups or 
speech communities that are defined by their socio-demographic variables. Individuals would merely serve as instances to which episodes of communication can be attributed (cf. Luhmann 1995 on Personen; or Holzer 2008 on Adressierbarkeit). ${ }^{18}$ As an ultimate step, single communicative events will be modelled as network knots, as has been exploratively shown in communicationoriented modelling as part of socionics. ${ }^{19}$ For historical developments also text networks are possible, where the text itself is the knot and the author only one of the text's attributes (Biber 1995; Mehler 2008). By modelling actualized communicative events, network analysis would also surmount its latent static and ahistorical bias (Stokman and Doreian 1997; Hollstein 2003; Albrecht 2008). All these points will contribute to create a de-personalized network analysis where the historically grown association with the theory of action is dissolved. ${ }^{20}$ Since network analysis outside of linguistics received crucial impulses from cybernetics, network models of different disciplines like sociology, ethnology, and information technology increasingly converge (Scott 1991). In this context, it should be possible in the long run to tie micro-level observation to the structures computed on the macro-level. Algebra of matrices has been applied to network data and has already shown Eigenbehavior of networks (Jansen 2006: 122).

\subsection{The environment of communication}

Accompanying work on structurally coupled autopoietic systems is necessary to understand the implications from operational closure and strong system/environment borders between biology, cognition, and communication. They are emergent entities in their own rights, and their discrete processes and structures must be studied as such. This safeguards against a general tendency towards neurorealism and socio-biology in the social sciences. One example is the processing

18 Social systems observe themselves in contrast to their environment and can thus create instances to which they ascribe episodes of communications. To mark the subjectless construction of the social process, Luhmann refers to these communicative constructions as "personae" (Luhmann 1995; SS 155; GdG 106-107; WdG 33-34), whereas other sociologists more consequently talk about “addresses” (Fuchs 2005). Qualitative interviews of individuals, research on awareness and attitudes, as well as classical diffusion research may be used to indirectly motivate phase transitions in communications.

19 Priority Programme "Socionics" by the German Research Foundation (DFG; 1999-2006; SPP 1077, especially the project "Communication-Oriented Modelling (COM): Modelling and simulation of social communication processes").

20 Cf. for a strong position on individual actions Wellman (1988), for a structure-oriented theory of action Burt (1992). With Luhmann, "action” is reduced to a category of ascription. 
of expectancy structures in cognitive systems. As discussed above, selections are conditioned by what I expect the other will expect from me. Is there a correlate of expectancy structures in structurally coupled cognitive systems? Newer studies on error-related negativities (ERN) under the term "anatomy of error" indicate that there is. ${ }^{21}$ At around 100 milliseconds after committing a wrongful action or observing a mistake, EEG-readings of the anterior cingulate cortex show a negative maximum. The mechanism includes, in addition, reward and punishment by releasing and blocking dopamine. Two aspects seem important: First, the time delay is too short for a conscious realization of the erroneousness of the stimulus; the neuropsychological mechanism can be regarded as automatized. Second, the brain includes expectations in the planning and execution of actions, and processes discongruencies between expected and actual events (Luck 2005: 47). There are also language-specific negativities, like the so-called N400 (Kutas and Hillyard 1980; Luck 2005: 45), which is sensitive to expectations from semantic contexts. The sentence "While I was visiting my home town, I had lunch with several old shirts” prompts a strong N400 amplitude (Luck 2005: 45). However, there are differences to the ERN events mentioned above: First, also expectable semantic elements prompt negativities, whose intensity depends on the degree of expectability. In other words, the amplitude of N400 correlates with the frequency of the item. Second, whereas N400 reflects language-specific brain activity, ERNs are universal. These results are highly discussed in their own domain and have not yet been put into the context of communicative theories. However, it might give an explanation for the emergence of expectancy structures in social systems. At the same time, it illustrates how fundamentally different a seemingly identical property appears on both sides of the system/environment border: Neuron potentials are not grammatical structures. The idea of a co-evolution of operationally closed systems should replace any notion of mutual determination in the long run, since it better captures the specific status of language between bodily function, cognition and Eigenbehavior of a dynamic-stable structure.

These three dimensions should indicate what kind of research design is needed to corroborate the position on language as a symbolic structure of social systems. As I tried to lay out, the different theoretical approach will reveal itself in a specific combination of established methods and their further development. However, the Theory of Social Systems - being the branch of systems theory closest to linguistic interests - can serve as a natural point of reference for all of these dimensions.

21 Cf. canonically Gehring et al. (1993); Dehaene et al. (1994); Holroyd and Coles (2002); on reception Schie et al. (2004). 
Acknowledgement: This article is a revised and expanded version of a presentation given at the nineteenth Congrès international des linguistes in Geneva in 2013.

\section{Sigla}

CGL. Saussure, Ferdinand de. 1983. Course in general linguistics. Transl. and annotated by Roy Harris. London: Duckworth.

CLG. Saussure, Ferdinand de. 2005 [1916/1967]. Cours de linguistique générale. Edition critique prepare par Tullio de Mauro. Paris: Edition Payot et Rivages.

ELG. Saussure, Ferdinand de. 2002. Ecrits de linguistique générale. Paris: Gallimard.

GdG. Luhmann, Niklas. 1997. Die Gesellschaft der Gesellschaft. Frankfurt/Main: Suhrkamp.

GLU. Baraldi, Claudio, Giancarlo Corsi \& Esposito, Elena. ${ }^{3} 1999$. Glossar zu Niklas Luhmanns Theorie sozialer Systeme. Frank- furt/Main: Suhrkamp.

SS. Luhmann, Niklas. 1984. Soziale Systeme. Grundriß einer allgemeinen Theorie. Frankfurt/ Main: Suhrkamp.

TC. Saussure, Ferdinand de. 1993. Troisième cours de linguistique générale (1910-1911) d'après les cahiers d'Émile Constantin. Ed. and transl. by Eisuke Komatsu and Roy Harris. Oxford/ Tokyo: Pergamon.

WdG. Luhmann, Niklas. 1990. Wissenschaft der Gesellschaft. Frankfurt/Main: Suhrkamp.

WGL. Saussure, Ferdinand de. 2006. Writings in general linguistics. Transl. by Carol Sanders. Oxford: OxfordUP.

\section{References}

Albrecht, Steffen. 2008. Netzwerke und Kommunikationen. Zum Verhältnis zweier sozialwissenschaftlicher Paradigmen. In Christian Stegbauer (ed.), Netzwerkanalyse und Netzwerktheorie. Ein neues Paradigma in den Sozialwissenschaften, 166-178. Wiesbaden: VS.

Albrecht, Jörn. 2000. Europäischer Strukturalismus. Ein forschungsgeschichtlicher Überblick. Tübingen: Francke.

Alexander, Jeffrey C. (ed.). 1987. The micro-macro link. Berkeley, CA: University of California Press.

Aristotle. 1955. De sensu et sensibilibus [Sense and sensibilia]. In W. D. Ross (ed.), Parva naturalia, 436a1-480b30. Oxford: Oxford University Press.

Auer, Peter. 2007. Hermann Pauls radikaler Kognitivismus. Versuch einer Neubewertung. Vortrag zur Eröffnung des "Hermann-Paul-Centrums für Linguistik," Freiburg: 18. Mai 2007. http://www.hpcl.uni-freiburg.de/assets/files/hermann_paul/hermann_pauls_ radikaler_kognitivismus.pdf (accessed 25 May 2015).

Austin, John L. [2003] 1962. How to do things with words. Cambridge: Harvard University Press. Baecker, Dirk. 2005. Form und Formen der Kommunikation. Frankfurt: Suhrkamp.

Ballauf, Theodor. 1984. "Organon" and "organismus." In Joachim Ritter (ed.), Historisches Wörterbuch der Philosophie, vol. 6, 1317-1326 and 1330-1336. Basel: Schwabe. 
Baraldi, Claudio, Giancarlo Corsi \& Elena, Esposito. 1999. Glossar zu Niklas Luhmanns Theorie sozialer Systeme. Frankfurt: Suhrkamp. [Reference to this work will be designated GLU]

Baudry, Jean-Louis. 1968. Linguistique et production textuelle. In Tel Quel, Théorie d'ensemble, 351-364. Paris: Édition du seuil.

Bénard, Henri. 1901. Les tourbillons cellulaires dans une nappe liquide propageant de la chaleur par convection en régime permanent. Paris: Gauthier-Villars dissertation.

Biber, Douglas. 1995. Dimensions of register variation. A cross-linguistic comparison. Cambridge: Cambridge University Press.

Bierbach, Christine. 1978. Sprache als "fait social." Die Linguistische Theorie F. de Saussures und ihr Verhältnis zu den positivistischen Sozialwissenschaften. Berlin: de Gruyter.

Binczek, Natalie. 2002. Medien- und Kommunikationstheorie. Neuere deutsche Literatur. In Claudia Benthin \& Hans Rudolph Velten (eds.), Germanistik als Kulturwissenschaft. Eine Einführung in neue Theoriekonzepte, 152-174. Reinbek: Rowohlt.

Bühler, Karl. 1978 [1934]. Sprachtheorie. Die Darstellungsfunktion der Sprache. Frankfurt: Ullstein.

Burt, Ronald S. 1992. Structural holes: The social structure of competition. Cambridge: Harvard University Press.

Buss, Mareike. 2007. Review of “Writings in general linguistics.” https://linguistlist.org/ issues/18/18-2536.html (accessed 26 June 2015).

Chomsky, Noam. 1965. Aspects of a theory of syntax. Cambridge, MA: MIT Press.

Chomsky, Noam. 1981. Lectures on government and binding. Dordrecht: Foris.

Coseriu, Eugenio. 1977. Tradición y novedad en la ciencia del lenguaje. Estudios de historia de la lingüistica. Madrid: Gredos.

Croft, William. 1996. Linguistic selection. An utterance-based evolutionary theory of language change. Nordic Journal of Linguistics 19. 99-139.

Croft, William. 2000. Explaining language change. An evolutionary approach. Harlow: Longman.

Croft, William. 2009. Towards a social cognitive linguistics. In Vyvyan Evans \& Stéphanie Pourcel (eds.), New directions in cognitive linguistics, 395-420. Amsterdam: Benjamins.

Croft, William. 2001. Radical construction grammar: Syntactic theory in typological perspective. Oxford: Oxford University Press.

Cull, Paul \& William Frank. 1979. Flaws of form. International Journal of General Systems 5. 201-211.

Davis, Garry W. 2008. Analogie, intrinsische Dauer und Prosodie. Zur postvokalischen Ausbreitung der ahd. Lautverschiebung im Fränkischen. Paul-Braune-Beiträge 130(3). 420-437.

Dehaene, Stanislas, Michael I. Posner \& Don M. Tucker. 1994. Localization of a neural system for error detection and compensation. Psychological Science 5(5). 303-305.

Doroszewski, Witold. 1933. Quelques remarques sur les rapports de la sociologie et de la linguistique. Durkheim et $\mathrm{F}$. de Saussure. Journale de psychologie normale et pathologique 30. 82-91.

Dosse, François. 1996. Geschichte des Strukturalismus, vol. 1. Hamburg: Junius.

Durkheim, Emile. 1956 [1895]. Les règles de la méthode sociologique. Paris: Presses Universitaires de France.

Esposito, Elena. 1993. Zwei-Seiten-Formen in der Sprache. In Dirk Baecker (ed.), Probleme der Form, 88-119. Frankfurt: Suhrkamp. 
Foerster, Heinz von. 1993. Für Niklas Luhmann. Wie rekursiv ist Kommunikation? Teoria sociologica 1(2). 61-85.

Fontdevila, Jorge, M. Pilar Opazo \& Harrison C. White. 2011. Order at the edge of chaos: Meaning from network switchings across functional systems. Sociological Theory 29. $178-189$.

Fried, Mirjam. 2013. Principles of constructional change. In Thomas Hoffmann \& Graeme Trousdale (eds.), The Oxford handbook of construction grammar, 419-437. Oxford: Oxford University Press.

Fuchs, Peter. 2005. Adressabilität als Grundbegriff der soziologischen Systemtheorie. In MarieChristin Fuchs (ed.), Konturen der Modernität. Systemtheoretische Essays II, 37-61. Bielefeld: Transcript.

Gabelentz, Georg von der. 1901. Die Sprachwissenschaft. Ihre Aufgaben, Methoden und bisherigen Ergebnisse. Leipzig: Tauchnitz.

Gadet, Françoise. 1989. Après Saussure. DRLAV - Revue de linguistique 40. 1-40.

Geeraerts, Dirk \& Gitte Kristiansen. 2014. Cognitive linguistics and linguistic variation. In Jeannette Littlemore \& John R. Taylor (eds.), Continuum companion to cognitive linguistics, 202-217. New York: Continuum.

Geeraerts, Dirk. 2005. Lectal variation and empirical data in cognitive linguistics. In Francisco J. Ruiz de Mendoza Ibáñez \& M. Sandra Peña Cervel (eds.), Cognitive linguistics: Internal dynamics and interdisciplinary interaction, 163-190.

Berlin: De Gruyter.

Gehring, W. J., B. Goss, M. G. H. Coles, D. E. Meyer \& E. Donchin. 1993. A neural system for error-detection and compensation. Psychological Science 4(6). 385-390.

Gibson, Edward \& Kenneth Wexler. 1994. Triggers. Linguistic Inquiry 25(3). 407-454.

Glanville, Ranulph. 1988. Objekte. Berlin: Merve.

Greve, Jens (ed.). 2008. Das Mikro-Makro-Modell der soziologischen Erklärung. Zur Ontologie, Methodologie und Metatheorie eines Forschungsprogramms. Wiesbaden: VS.

Harder, Peter. 2010. Meaning in mind and society. A functional contribution to the social turn in cognitive linguistics. Berlin: De Gruyter.

Heider, Fritz. 2005 [1926]. Ding und Medium. Reprint, Berlin: Kadmos.

Heylen, Kris, José Tummers \& Dirk Geeraerts. 2008. Methodological issues in corpus-based cognitive linguistics. In Gitte Kristiansen \& René Dirven (eds.), Cognitive sociolinguistics: Language variantion, cultural models, social systems, 91-128. Berlin: De Gruyter.

Hiersche, Rolf. 1972. F. de Saussure's langue-parole-Konzeption und sein Verhältnis zu Durkheim und G. von der Gabelentz. Innsbruck: Institut für vergleichende Literaturwissenschaft.

Hjelmslev, Louis. 1942. Langue et parole. Cahiers Ferdinand de Saussure 2. 29-44.

Hjelmslev, Louis. 1961. Prolegomena to a theory of language. Madison, WI: University of Wisconsin Press.

Hollstein, Bettina. 2003. Netzwerkveränderungen verstehen. Zur Integration von struktur- und akteurstheoretischen Perspektiven. Berliner Journal für Soziologie 13(2). 153-174.

Holroyd, Clay B., \& Michael G. H. Coles. 2002. The neural basis of human error processing. Reinforcement learning, dopamine, and the error-related negativity. Psychological Review 109(4). 679-709.

Holzer, Boris. 2008. Netzwerke und Systeme. Zum Verhältnis von Vernetzung und Differenzierung. In Christian Stegbauer (ed.), Netzwerkanalyse und Netzwerktheorie. Ein neues Paradigma in den Sozialwissenschaften, 156-164. Wiesbaden: VS. 
Hutton, Christopher M. 1990. Abstraction and instance: The type-token relation in linguistic theory. Oxford: Pergamon.

Hutton, Christopher M. 2013. Fictions of affinity and the Aryan paradigm. In Ottmar Ette \& Markus Messling (eds.), Wort Macht Stamm. Rassismus und Determinismus in der Philologie, 89-103. Munich: Fink.

Jakobson, Roman 0. 1960. Linguistics and poetics. In Thomas A. Sebeok (ed.), Style in language, 350-377. Cambridge: MIT Press.

Jansen, Dorothea. 2006. Einführung in die Netzwerkanalyse. Grundlagen, Methoden, Forschungsbeispiele. Wiesbaden: VS.

Keller, Rudi. 1994 [1990]. On language change: The invisible hand in language. London \& New York: Routledge.

Kieserling, André. 1996. Die Autonomie der Interaktion. In Günther Küppers (ed.), Chaos und Ordnung. Formen der Selbstorganization in Natur und Gesellschaft, 257-289. Stuttgart: Reclam.

Koerner, Ernst F. K. 1973. Ferdinand de Saussure. Origin and development of his linguistic thought in Western studies of language. A contribution to the history and theory of linguistics. Braunschweig: Vieweg.

Köller, Wilhelm. 2012. Sinnbilder für Sprache. Metaphorische Alternativen zur begrifflichen Erschließung von Sprache. Berlin: De Gruyter.

Kristiansen, Gitte \& René Dirven (eds.). 2008. Cognitive sociolinguistics: Language variantion, cultural models, social systems. Berlin: De Gruyter.

Künzler, Jan. 1987. Grundlagenprobleme der Theorie symbolisch generalisierter Kommunikationsmedien bei Niklas Luhmann. Zeitschrift für Soziologie 16. 317-333.

Küppers, Günther (ed.). 1996. Chaos und Ordnung. Formen der Selbstorganization in Natur und Gesellschaft. Stuttgart: Reclam.

Küppers, Günther \& Rainer Paslack. 1996. Die natürlichen Ursachen von Ordnung und Organization. In Günther Küppers (ed.), Chaos und Ordnung. Formen der Selbstorganization in Natur und Gesellschaft, 44-60. Stuttgart: Reclam.

Kutas, Marta \& Stephen A. Hillyard. 1980. Reading senseless sentences: Brain potentials reflect semantic incongruity. Science 207(4427). 203-205.

Landsbergen, Frank, Robert Lachlan, Carel ten Cate \& Arie Verhagen. 2010. A cultural evolutionary model of patterns in semantic change. Linguistics 48. 363-390.

Langacker, Ronald W. 1987. Foundations of cognitive grammar, vol. 1. Stanford, CA: Stanford University Press.

Lass, Roger. 1997. Historical linguistics and language change. Cambridge: Cambridge University Press.

Lightfoot, David W. 1991. How to set parameters. Arguments from language change. Cambridge, MA: MIT Press.

Luck, Steven J. 2005. An introduction to the event-related potential technique. Cambridge, MA: MIT Press.

Luhmann, Niklas. 1977. Interpenetration. Zum Verhältnis personaler und sozialer Systeme. Zeitschrift für Soziologie 6. 62-76.

Luhmann, Niklas. 1984. Soziale Systeme. Grundriß einer allgemeinen Theorie. Frankfurt: Suhrkamp. [Reference to this work will be designated SS.]

Luhmann, Niklas. 1987. Sprache und Kommunikationsmedien. Ein schieflaufender Vergleich. Zeitschrift für Soziologie 16. 467-468.

Luhmann, Niklas. 1990. Wissenschaft der Gesellschaft. Frankfurt: Suhrkamp. [WdG] 
Luhmann, Niklas. 1992. The form of writing. Stanford Literature Review 9. 25-42.

Luhmann, Niklas. 1993. Zeichen als Form. In Dirk Baecker (ed.), Probleme der Form, 45-69. Frankfurt/Main: Suhrkamp. [Reference to this work will be designated ZaF.]

Luhmann, Niklas. 1995. Die Form “Person." In Niklas Lukmann (ed.), Die Soziologie und der Mensch (Soziologische Aufklärung 6), 137-148. Opladen: Westdeutscher Verlag.

Luhmann, Niklas. 1997. Die Gesellschaft der Gesellschaft. Frankfurt: Suhrkamp. [Reference to this work will be designated GdG.]

Luhmann, Niklas. 1997. Die Kunst der Gesellschaft. Frankfurt/Main: Suhrkamp. [Reference to this work will be designated KdG.]

Luhmann, Niklas. 2009. Einführende Bemerkungen zu einer Theorie symbolisch generalisierter Kommunikationsmedien. In Niklas Lukmann (ed.), Aufsätze zur Theorie der Gesellschaft (Soziologische Aufklärung 2), 212-241. Wiesbaden: VS.

Martinet, André. 1955. Economie des changements phonétiques. Berne: Francke.

Maturana, Humberto R. 1988. Ontology of observing: The biological foundations of self-consciousness and the physical domain of existence. Conference workbook: Texts in cybernetics, American Society For Cibernetics Conference, Felton, CA, 18-23 October.

Maturana, Humberto R. \& Francesco J. Varela. 1980. Autopoiesis and cognition: The realization of the living. Dordrecht: Reidel.

Maturana, Humberto R. \& Francesco J. Varela. 1984. Der Baum der Erkenntnis. Die biologischen Wurzeln des menschlichen Erkennens. Munich: Goldmann.

Mead, George H. 1934. Mind, self, and society: From the standpoint of a social behaviorist. Chicago: University of Chicago Press.

Mehler, Alexander. 2008. Large text networks as an object of corpus linguistic studies. Handbooks of Linguistics and Communication Science 29(1). 328-382.

Milroy, Lesley \& James Milroy. 1992. Social networks and social class. Towards an integrated sociolinguistic model. Language in Society 21(1). 1-26.

Mounin, Georges. 1971. Saussure ou le structuraliste sans le savoir. Paris: Seghers.

Mounin, Georges. 1975 [1972]. Clefs pour la sémantique. Paris: Seghers.

Parsons, Talcott, Edward Albert Shils \& Neil J. Smelser. 1951. Some fundamental categories of the theory of action. A general statement. In Talcott Parsons \& Edward A. Shils (eds.), Toward a general theory of action: Theoretical foundations for the social sciences, 3-29. Cambridge: Harvard University Press.

Paslack, Rainer. 1996. Sagenhaftes Chaos. Der Ursprung der Welt im Mythos. In Günther Küppers (ed.), Chaos und Ordnung. Formen der Selbstorganization in Natur und Gesellschaft, 11-27. Stuttgart: Reclam.

Paul, Hermann. 1960 [1880]. Prinzipien der Sprachgeschichte. Tübingen: Niemeyer.

Ritt, Nikolaus. 2004. Selfish sounds and linguistic evolution: A Darwinian approach to language change. Cambridge: Cambridge University Press.

Ropohl, Günter. 1978. Einführung in die allgemeine Systemtheorie. In Hans Lenk \& Günter Ropohl (ed.), Systemtheorie als Wissenschaftsprogramm, 9-49. Königstein: Athenäum.

Saussure, Ferdinand de. 1983. Course in general linguistics, Roy Harris (trans.). London: Duckworth. [Reference to this work will be designated CGL.]

Saussure, Ferdinand de. 1993. Troisième cours de linguistique générale (1910-1911) d'après les cahiers d'Émile Constantin, Eisuke Komatsu \& Roy Harris (trans. \& ed.). Oxford \& Tokyo: Pergamon. [Reference to this work will be designated TC.]

Saussure, Ferdinand de. 2002. Ecrits de linguistique générale. Paris: Gallimard. [Reference to this work will be designated ELG.] 
Saussure, Ferdinand de. 2005 [1916/1967]. Cours de linguistique générale, Tullio de Mauro (ed.). Paris: Edition Payot et Rivages. [Reference to this work will be designated CLG.]

Saussure, Ferdinand de. 2006. Writings in general linguistics, Carol Sanders (trans.). Oxford: Oxford University Press. [Reference to this work will be designated WGL.]

Scheerer, Thomas M. 1980. Ferdinand de Saussure. Rezeption und Kritik. Darmstadt: Wiss. Buchgesellschaft.

Scheibmayr, Werner. 2004. Niklas Luhmanns Systemtheorie und Charles S. Peirce Zeichentheorie. Zur Konstruktion eines Zeichensystems. Tübingen: Niemeyer.

Schie, Hein T. van, Rogier B. Mars, Michael G. H. Coles \& Harold Bekkering. 2004. Modulation of activity in medial frontal and motor cortices during error observation. Nature Neuroscience 7(5). 549-554.

Schiewek, Werner. 1992. Zum vernachlässigten Zusammenhang von "symbolischer Generalisierung" und "Sprache" in der Theorie sozialer Systeme. In Werner Krawietz \& Michael Welker (eds.), Kritik der Theorie sozialer Systeme. Auseinandersetzungen mit Luhmanns Hauptwerk, 147-161. Frankfurt: Suhrkamp.

Schleicher, August. 1873 [1863]. Die Darwinsche Theorie und die Sprachwissenschaft. Offenes Sendschreiben an Herrn Dr. Ernst Häckel. Weimar: Böhlau.

Schützeichel, Rainer. 2004. Soziologische Kommunikationstheorien. Konstanz: UVK.

Scott, John. 1991. Social network analysis: A handbook. London: Sage.

Searle, John R. 1969. Speech acts: An essay in the philosophy of language. Cambridge: Cambridge University Press.

Seiffert, Helmut. 1992. Handlungstheorie, Modellogik, Ethik, Systemtheorie [Einführung in die Wissenschaftstheorie 3]. Munich: Beck.

Shannon, Claude E. \& Warren Weaver. 1972 [1949]. The mathematical theory of communication. Urbana, IL: University of Illinois Press.

Simon, Fritz B. 1993. Mathematik und Erkenntnis. Eine Möglichkeit, die "Laws of Form" zu lesen. In Dirk Baecker (ed.), Kalkül der Form, 38-57. Frankfurt: Suhrkamp.

Spencer-Brown, George. 1969. Laws of form. London: Allen \& Unwin.

Stanitzek, Georg. 1997. Systemtheorie? Anwenden? In Helmut Brackert \& Jörn Stückrath (eds.), Literaturwissenschaft. Ein Grundkurs, 650-663. Reinbek: Rowohlt.

Steels, Luc (ed.). 2011. Design patterns in fluid construction grammar. Amsterdam: Benjamins.

Stokman, Frans N. \& Patrick Doreian. 1997. Evolution of social networks: Processes and principles. In Patrick Doreian \& Frans N. Stokman (eds.), Evolution of social networks, 233-250. Amsterdam: Gordon and Breach.

Tummers, José, Kris Heylen \& Dirk Geeraerts. 2005. Usage-based approaches in cognitive linguistics: A technical state of the art. Corpus Linguistics and Linguistic Theory 1-2. 225-261.

Varela, Francisco J. \& Humberto R. Maturana. 1974. Autopoiesis: The organization of living systems, its characterization and a model. Biosystems 5. 187-196.

Varela, Francisco J. 1975. A calculus for self-reference. International Journal of General Systems 2. 5-24.

Venema, Johannes. 1997. Zum Stand der zweiten Lautverschiebung im Rheinland. Diatopische, diachrone und diastratische Untersuchungen am Beispiel der dentalen Tenuis vorahd. /t/. Stuttgart: Steiner.

Verhagen, Arie. 2005. Constructions of intersubjectivity: Discourse, syntax, and cognition. Oxford: Oxford University Press. 
Washabaugh, William. 1974. Saussure, Durkheim, and sociolinguistic theory. Archivum Linguisticum 5. 25-34.

Weinreich, Uriel, William Labov \& Marvin I. Herzog. 1968. Empirical foundations for a theory of language change. In Winfried P. Lehmann \& Yakov Malkiel (eds.), Directions for historical linguistics, 95-188. Austin, TX: University of Texas Press.

Weizsäcker, Carl F. von. 1971. Die Einheit der Natur. Munich: Hanser.

Wiener, Norbert. 1948. Cybernetics: Or control and communication in the animal and the machine. Paris: Hermann.

Wellman, Barry. 1988. Structural analysis. From method and metaphor to theory and substance. In Barry Wellman \& Stephen D. Berkowitz (eds.), Social structures: A network approach, 19-61. Cambridge: Cambridge University Press.

Willems, Klaas. 2011. Meaning and interpretation. The semiotic similarities and differences between Cognitive Grammar and European structural linguistics. Semiotica 185(1/4). 1-50.

Wunderli, Peter. 1981. Saussure-Studien. Exegetische und wissenschaftsgeschichtliche Untersuchungen zum Werk von F. de Saussure. Tübingen: Narr.

Zeige, Lars Erik. 2011. Sprachwandel und soziale Systeme. Hildesheim: Olms.

Zeige, Lars Erik. 2014. On cognition and communication in usage-based models of language change. In Evie Coussé \& Ferdinand von Mengden (eds.), Usage-based approaches to language change, 49-80. Amsterdam: Benjamins. 